\title{
Mechanosensitive Ion Channels in Cultured Sensory Neurons of Neonatal Rats
}

\author{
Hawon Cho, Jieun Shin, Chan Young Shin, Soon-Youl Lee, and Uhtaek Oh \\ The Sensory Research Center, Creative Research Initiatives, College of Pharmacy, Seoul National University, \\ Seoul 151-742, Korea
}

\begin{abstract}
Mechanosensitive (MS) ion channels are present in a variety of cells. However, very little is known about the ion channels that account for mechanical sensitivity in sensory neurons. We identified the two most frequently encountered but distinct types of MS channels in 1390 of 2962 membrane patches tested in cultured dorsal root ganglion neurons. The two MS channels exhibited different thresholds, thus named as low-threshold (LT) and high-threshold (HT) MS channels, and sensitivity to pressure. The two channels retained different single-channel conductances and current-voltage relationships: LT and HT channels elicited large- and small-channel conductance with outwardly rectifying and linear $I-V$ relationships, respectively. Both LT and HT MS channels were permeable to monovalent cations and $\mathrm{Ca}^{2+}$ and were blocked by gadolinium, a blocker of
\end{abstract}

The mechanical stimulation of sensory receptors in vertebrates may generate a variety of sensations, such as touch, pressure, vibration, proprioception, and pain. Neural signals of the somatic sensations begin with the excitation of mechanoreceptors in sensory nerves. Numerous specialized or encapsulated endings in the skin are mechanoreceptors that are sensitive to light touch, pressure, or vibration (Winkelmann, 1986; Willis and Coggeshall, 1991). In addition, a subset of A $\delta$-mechanical and C-polymodal nociceptors are sensory organs that respond to intense mechanical stimuli, and therefore, subserve pain sensation. Moreover, each mechanoreceptor responds uniquely to various temporal and spatial mechanical stimuli. Combinations of these mechanoreceptors gives rise to a repertoire of sensations caused by complex mechanical stimuli (Gardner et al., 2000).

Mechanoreceptor excitation is accomplished by opening or closing ion channels present in the sensory organs. Many different types of mechanosensitive (MS) channels have been characterized in a wide variety of cell types (Garcia-Anoveros and Corey, 1997; Hamill and Martinac, 2001). These MS channels are involved in various cellular functions, such as osmoregulation, touch, hearing, or control of balance (Garcia-Anoveros and Corey, 1997; Hamill and Martinac, 2001). Recently a group of genes, related to mechanosensation was cloned in genetic mutants of Caenorhabditis elegans or Drosophila melanogaster. Among these, mec-4 and mec-10 cloned from Caenorhabditis elegans were

\footnotetext{
Received Aug. 13, 2001; revised Nov. 27, 2001; accepted Nov. 29, 2001.

The present study was supported by Creative Research Initiatives of the Ministry of Science and Technology of Korea and in part by a BK21 program. We thank Dr. Donghee Kim for his critical reading of this manuscript.

Correspondence should be addressed to Dr. Uhtaek Oh, Sensory Research Center, CRI, Seoul National University, College of Pharmacy, Kwanak, Shinlim San 56-1, Seoul 151-742, Korea. E-mail: utoh@plaza.snu.ac.kr.

Copyright (ㄷ) 2002 Society for Neuroscience $0270-6474 / 02 / 221238-10 \$ 15.00 / 0$
}

MS channels. Colchicine and cytochalasin D markedly reduced the activities of the two MS channels, indicating that cytoskeletal elements support the mechanosensitivity. Both types of MS channels were found primarily in small sensory neurons with diameters of $<30 \mu \mathrm{m}$. Furthermore, HT MS channels were sensitized by a well known inducer of mechanical hyperalgesia, prostaglandin $E_{2}$, via the protein kinase A pathway. We identified two distinct types of MS channels in sensory neurons that probably give rise to the observed MS whole-cell currents and transduce mechanical stimuli to neural signals involved in somatosensation, including pain.

Key words: mechanosensitive channels; cationic; sensory neurons; somatosensation; pain; sensitization implicated in mechanosensitivity, because mutations in these genes caused the loss of touch sensitivity in nematodes (Driscoll and Chalfie, 1991; Mitani et al., 1993; Huang and Chalfie, 1994). NompC in Drosophila encoding a protein homologous to transient receptor potential channels is also implicated in mechanosensitivity because of reduction in bristle mechanoreceptor currents in null mutants (Walker et al., 2000). In addition, vanilloid receptorrelated osmotically activated channel (VR-OAC), a gene that shares homology with vanilloid receptor 1 and encodes osmotically-activated ion channels, has been identified in Merkel cells surrounding the vibrissae of the rat snout (Liedtke et al., 2000). Although these genes appear to be related to mechanosensitivity, evidence that products of these genes are gated mechanically is still lacking (Tavernarakis and Driscoll, 1997).

Although many MS channels have been identified in a variety of cells, MS channels in sensory neurons are not well characterized. Recently, whole-cell currents activated by stretch or pressure in dorsal root ganglion (DRG) neurons have been identified (McCarter et al., 1999; Takahashi and Gotoh, 2000). The reversal potential of the stretch-activated whole-cell current was near zero in $\mathrm{Na}^{+} / \mathrm{K}^{+}$bi-ionic solution and blocked by gadolinium, a nonspecific MS channel blocker (McCarter et al., 1999). Although whole-cell currents evoked by stretch or pressure have been characterized in sensory neurons, ion channels responsible for the macroscopic mechanically gated currents have not yet been characterized in sensory neurons. Furthermore, despite the identification of molecular species for detecting certain modes of pain sensation (Caterina and Julius, 1999), ion channels responsible for the excitation of sensory neurons by intense mechanical force are not well characterized. In this study, we identified the singlechannel currents of two distinct types of MS channels in cultured 
rat DRG neurons and characterized the biophysical properties of these channels.

\section{MATERIALS AND METHODS}

Cell culture. Experiments were performed according to the Ethical Guidelines of the International Association for the Study of Pain. DRGs were dissected from all levels of the thoracic and lumbar spinal cords of neonatal rats and collected in cold culture medium $\left(4^{\circ} \mathrm{C}\right)$. The culture medium, a mixture of DMEM and F-12 solution (Invitrogen, Grand Island, NY), contained 10\% fetal bovine serum (Invitrogen), $1 \mathrm{~mm}$ sodium pyruvate, $50-100 \mathrm{ng} / \mathrm{ml}$ nerve growth factor (Invitrogen), and $100 \mathrm{U} / \mathrm{ml}$ penicillin-streptomycin (Sigma). Ganglia were washed with a mixture of DMEM and F-12 solution and incubated for $30 \mathrm{~min}$ in a warm $\left(37^{\circ} \mathrm{C}\right)$ DMEM-F-12 mixture containing $1 \mathrm{mg} / \mathrm{ml}$ of collagenase (Worthington Biomedical, Freehold, NJ). The ganglia were then washed three times with $\mathrm{Mg}^{2+}$ - and $\mathrm{Ca}^{2+}$-free HBSS (Invitrogen), and incubated with gentle shaking for $30 \mathrm{~min}$ in warm HBSS $\left(37^{\circ} \mathrm{C}\right)$ containing $2.5 \mathrm{mg} / \mathrm{ml}$ of trypsin (Boehringer Mannheim, Indianapolis, IN). The trypsincontaining solution was then centrifuged at $1000 \mathrm{rpm}$ for $10 \mathrm{~min}$, and the pellet obtained was washed gently $2-3$ times with the culture medium to inhibit the enzyme activity. The pellet was suspended in the culture medium, gently triturated with a fire-polished Pasteur pipette, and plated onto round glass coverslips in small Petri dishes $(35 \times 12 \mathrm{~mm})$. The glass coverslips were previously treated with poly-L-lysine $(0.5 \mathrm{mg} / \mathrm{ml})$ and dried. Cells were placed in $37^{\circ} \mathrm{C}$ incubator in a $95 \%$ air and $5 \% \mathrm{CO}_{2}$ atmosphere. Cells were used 2-4 d after plating.

Electrophysiology. As soon as a borosilicate glass pipette (World Precision Instruments, Saratoga, FL) coated with Sylgard (Dow Corning, Midland, MI) touched the surface of a cultured sensory neuron, gentle suction was applied to the pipettes to obtain gigaseals. The tip resistance of the pipette was $\sim 3 \mathrm{M} \Omega$ for whole-cell and single-channel current recordings. To record whole-cell currents, gigaseals were formed first, and then the membrane in contact with the pipette was ruptured by applying gentle suction. After a whole cell was formed, the capacitive transients were canceled. For single-channel current recording, cellattached, outside-out, and inside-out patches were formed. Channel currents were recorded with a patch-clamp amplifier (Axopatch 200A; Axon Instruments, Foster City, CA) and filtered at $5 \mathrm{kHz}$ using a low-pass Bessel filter. The output of the amplifier was digitized at a sampling rate of 94 kilosamples per second with a digital data recorder (VR-10B; Instrutech, Great Neck, NY) and stored on videotapes. For chart recording, the output of the amplifier was filtered at $500 \mathrm{~Hz}$ with an eight-pole, low-pass Bessel filter (Frequency Devices, Haverhill, MA) and then fed to a thermal array chart recorder (TA240; Gould, Valley View, $\mathrm{OH})$.

The output of the digital data recorder was imported to a personal computer to analyze open and closed events of single-channel currents using Fetchex and Fetchan in pClamp (version 6.0.4; Axon Instruments). The threshold amplitude for taking an opening event was set at $50 \%$ (half-amplitude algorithm in Fetchan). The minimum duration of open events was set at $100 \mu \mathrm{sec}$ for measuring channel open probability $\left(P_{\mathrm{o}}\right)$ or amplitude histograms. $P_{\mathrm{o}}$ of single-channels was obtained from the equation (Spruce et al., 1985),

$$
P_{\mathrm{o}}=\left(\sum_{\mathrm{j}=1}^{\mathrm{N}} t_{\mathrm{j}} \mathrm{j}\right) / T N
$$

where $t_{\mathrm{j}}$ represents the time spent at each level, $j$ corresponding to 1,2 , ..., $\mathrm{N}$ channels open ( $N$ is the maximum number of channels seen in a patch), and $T$ is the duration of the recording. Channel activity $\left(N P_{\mathrm{o}}\right)$ was calculated as the maximum number $(N)$ of functional channels in the patch times $P_{\mathrm{o}}$. The maximum number $(N)$ of channels was determined after full activation of the channels by applying up to $-110 \mathrm{mmHg}$. The amplitude histograms were analyzed for patches containing only one or two channels.

Pressure application. Membrane stretch was achieved by the application of negative (suction) or positive pressures to a patch electrode. Pressures were applied as follows: the end of a 30-cm-high U-tube manometer filled with mercury was connected to a patch pipette with a polyethylene tube. When negative or positive pressure was applied to the patch pipette, the pressure was delivered to the manometer. Difference in the height of mercury columns in the manometer represented the actual pressure expressed in millimeters of mercury applied to the pipette. The polyethylene tube was also connected to a pressure transducer (P23XL-1; Gould) to record the pressure in a chart recorder.
Solution and chemicals. For whole-cell current recording, the pipette solution contained (in mM): $140 \mathrm{KCl}, 2 \mathrm{MgCl}_{2}, 5$ EGTA, $10 \mathrm{HEPES}, 2$ ATP, and 0.3 GTP, pH 7.2. The control bath solution for whole-cell recording contained (in $\mathrm{mM}$ ): $140 \mathrm{NaCl}, 5 \mathrm{KCl}, 2 \mathrm{MgCl}_{2}, 2 \mathrm{CaCl}_{2}$, and 10 HEPES, pH 7.2. For single-channel recording, the solution in the bath and the pipettes contained (in mM): $140 \mathrm{NaCl}, 5 \mathrm{KCl}, 2 \mathrm{MgCl}_{2}, 5$ EGTA, and 10 HEPES, pH 7.2, unless described otherwise. Colchicine (Sigma), gadolinium $\left(\mathrm{Gd}^{3+}\right.$; Sigma), and dibutyryl cAMP (Biomol, Plymouth Meeting, PA) were dissolved and stored in distilled water. Cytochalasin $\mathrm{D}$ (Sigma) and prostaglandin $\mathrm{E}_{2}$ (Sigma) were dissolved and stored in $100 \%$ ethanol. Amiloride (Sigma), H-89 (Biomol), and arachidonic acid (Sigma) were dissolved and stored in 100\% DMSO. All other basic agents for cell culture and the physiological solutions were purchased from Sigma.

Statistics. The paired Student's $t$ test was used for comparing two means. To compare multiple means, one-way ANOVA was used followed by a Tukey's post hoc test. To determine whether cell-size distributions of neurons containing two different MS channels were different, contingency tables were constructed, and a Fisher's exact test was used. A $p$ value $<0.05$ was considered significant.

\section{RESULTS}

\section{Suction protocol to form a gigaseal}

Because the magnitude of suction pressure applied to membrane patches during gigaseal forming affects the mechanosensitivity of certain MS channels (Hamill and McBride, 1997), we measured the suction pressure when gigaseals were formed. The suction pressure required was $3.8 \pm 0.15 \mathrm{mmHg}(n=10)$, which was considerably less than the suction pressure that changes the properties of mechanically gated channels present in Xenopus oocytes (Hamill and McBride, 1997). In addition, there was no indication of volume change of the cells or blebbing during or after pressure application, which is also thought to affect the mechanosensitivity of the MS channels (Hamill and McBride, 1997). As size of the patch pipettes is also a factor, which affects MS channels (Hamill and McBride, 1992), the inner diameters of the glass pipettes were measured using a scanning electron microscope. The average inner diameter of the patch pipettes used for recording whole-cell and single-channel currents was $1.4 \pm 0.09 \mu \mathrm{m}(n=6)$.

\section{Activation of MS whole-cell currents}

Whole-cell currents activated by pressure were recorded from cultured DRG neurons. As shown in Figure 1, inward currents were observed after positive pressures of 15 and $20 \mathrm{mmHg}$ were applied to the whole-cell pipette. The currents were activated by the pressure with an apparent 1-3 sec delay between currents and the plateaus of pressures as observed by others (Takahashi and Gotoh, 2000) and returned to the basal level when the pressures were released. Whole cells were too fragile to be maintained during pressure application when positive pressures exceeded 20 $\mathrm{mmHg}$ or were prolonged for more than $\sim 5 \mathrm{sec}$. The whole-cell currents were largely pressure-dependent: a greater current was observed when a higher pressure was delivered to patch pipettes (Fig. 1A,B). Pressure threshold, the lowest pressure tested to activate currents, varied among neurons, and was as low as 5 $\mathrm{mmHg}$. These whole-cell currents were activated by $5-20 \mathrm{mmHg}$ pressure in $81(28.9 \%)$ of 280 DRG neurons. The current-voltage relationships of MS whole-cell currents were obtained after applying voltage ramps of $300 \mathrm{msec}$ duration ranging from -100 to $+100 \mathrm{mV}$ before and during pressure application. Each current trace was averaged after two trials of the voltage ramps. MS whole-cell currents were defined after subtracting current response to the voltage ramp obtained before pressure application from that obtained during pressure application. As shown in Figure $1 C$, the subtraction current reversed at $-13.4 \pm 1.48 \mathrm{mV}$ $(n=18)$, suggesting poor cation selectivity. 

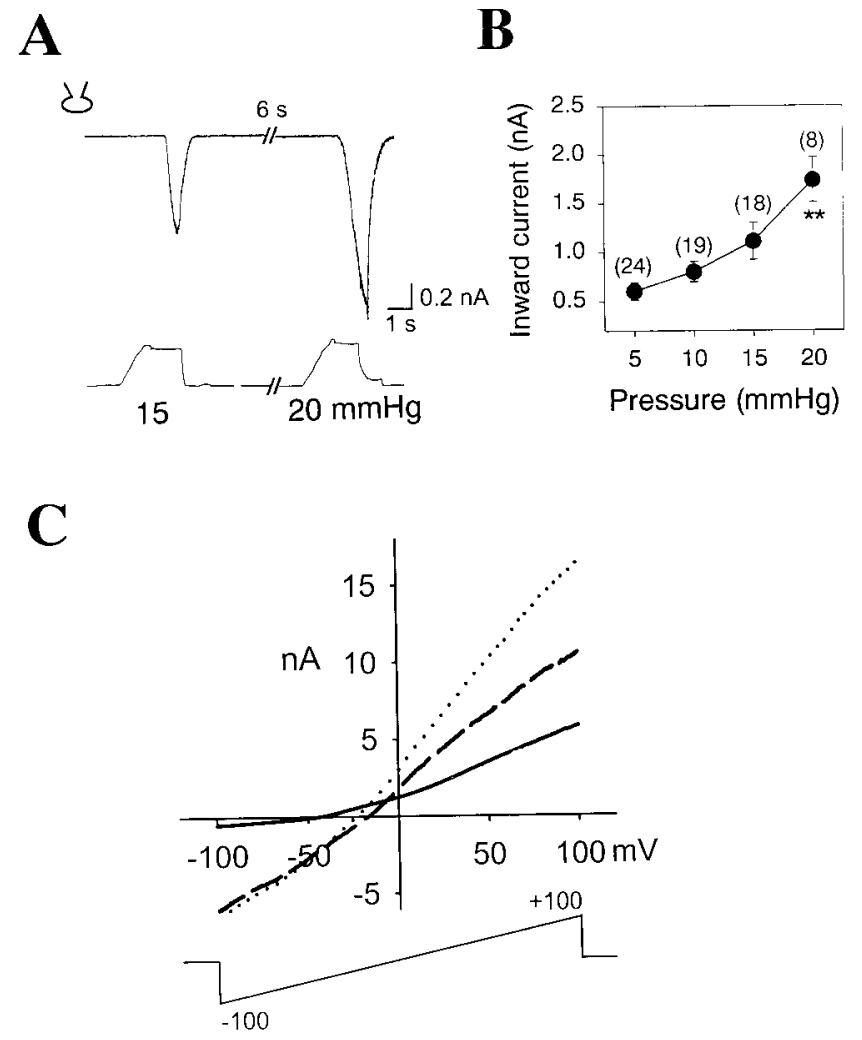

Figure 1. Activation of MS whole-cell currents by pressure. A, Top trace, Whole-cell currents of a cultured sensory neuron activated by pressure. Bottom trace, Positive pressures applied to the patch pipette. B, A summary of MS whole-cell currents in sensory neurons. Because of the fragile nature of whole cells, positive pressures of $<20 \mathrm{mmHg}$ were applied to whole cells. Membrane potential was held at $-60 \mathrm{mV}$. ${ }^{* *} p<0.01$ compared with the mean of whole-cell currents activated by $5 \mathrm{mmHg}$. Numbers in parentheses represent the number of experiments. $C$, Currentvoltage relationship of the whole-cell current activated by pressure. Voltage ramps (bottom trace) ranging from -100 to $+100 \mathrm{mV}$ with $300 \mathrm{msec}$ duration were applied before and during pressure application. Current elicited before pressure (solid line), during pressure application (dotted line), and difference current (dashed line).

\section{Activation of mechanosensitive single-channel currents}

To identify single-channel currents activated by pressure, cellattached or inside-out membrane patches were formed, and either negative or positive pressure was delivered to the shank of the patch pipette to activate MS channels. In membrane patches of cultured sensory neurons, application of capsaicin caused a great activation of single-channel currents, because of the ubiquitous presence of capsaicin-activated channels in cultured sensory neurons (Oh et al., 1996; Jung et al., 1999; Hwang et al., 2000). Single-channel currents activated by capsaicin, however, were not sensitive to pressure applied to the pipettes. To prevent the casual openings of capsaicin-activated channels, $10 \mu \mathrm{M}$ capsazepine, an antagonist of the capsaicin receptor, was added to the bath solution throughout the experiments.

We tested a total of 2962 cell-attached, outside-out, or insideout membrane patches of DRG neurons to determine the presence of MS channels. In cell-attached patches with the holding potential of $-60 \mathrm{mV}$, no single-channel currents were observed before applying suction, except for a few patches, which showed spontaneous openings of single-channel currents, possibly caused by initial pressures $<5 \mathrm{mmHg}$ applied to the pipettes during
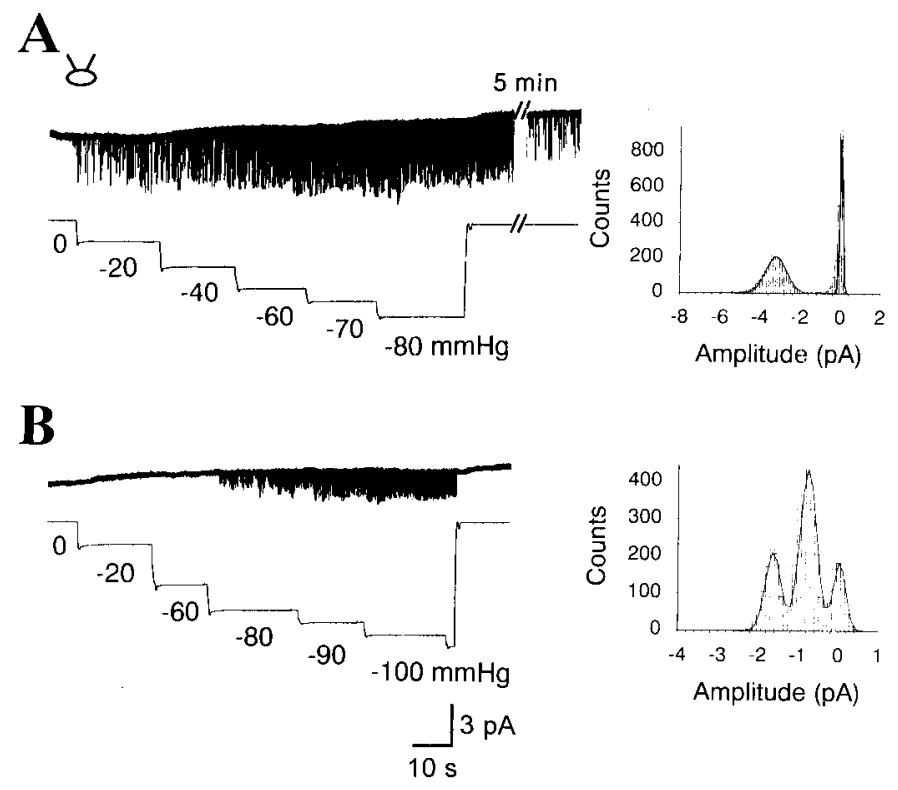

C

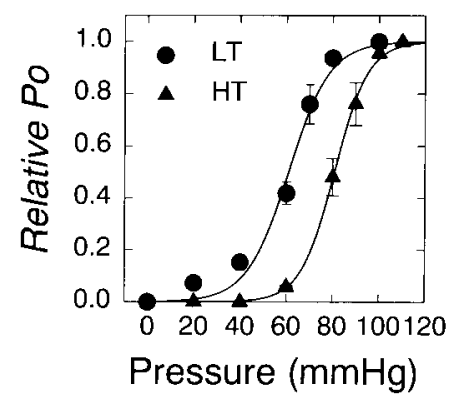

Figure 2. Single-channel currents activated by negative pressures applied to a cell-attached patch. $A$, This channel was classified as an LT MS channel because the channel was activated by a relatively low pressure. $E_{\text {hold }}=-60 \mathrm{mV}$. Right, An amplitude histogram of the single-channel currents. The mean amplitudes of LT MS channels were best fitted by a Gaussian distribution. $B$, Another type of single-channel currents activated only by negative pressures greater than $-80 \mathrm{mmHg}$. The channel was classified as an HT MS channel because of its high pressure threshold. The cell-attached patch contained two HT channels. Right, An amplitude histogram of the single-channel currents. $C$, Pressure-response relationships of the LT ( filled circle; $n=9$ ) and HT ( filled triangle; $n=9)$ MS channels. Relative channel activity $\left(N P_{\mathrm{o}} /\right.$ $N P_{\text {max }}$ ) at each pressure was fitted to the Boltzmann distribution described in Results. Bars represent SEM.

gigaseal formation. Two types of channels were observed most frequently when negative pressures of various magnitudes were applied to the pipettes (Fig. 2, Table 1).

One type of MS channel, called a low-threshold (LT) MS channel, was activated by relatively low pressures, -10 to -20 mmHg (Fig. 2A). Channel activity increased as higher pressures were applied to the patch and reached a maximum at $-80 \mathrm{mmHg}$. Interestingly, channel openings continued for a period of time even after the suction had been released. The residual LT channel activity, however, slowly declined after the negative pressure was removed (Fig. $2 A$ ). The LT channel was also activated by positive pressure up to $+80 \mathrm{mmHg}$ (data not shown). However, positive pressures broke membrane patches easily. Therefore, most of the single-channel currents were recorded with negative pressures applied to the patch pipettes. The LT MS channel was observed 


\begin{tabular}{|c|c|c|c|c|c|c|c|c|}
\hline Type & $\begin{array}{l}\text { Pressure } \\
\text { threshold } \\
(\mathrm{mmHg})\end{array}$ & $\begin{array}{l}P_{1 / 2} \\
(\mathrm{mmHg})\end{array}$ & Conductance $(\mathrm{pS})^{a}$ & $\begin{array}{l}\text { Proportion } \\
\text { (\# of patches) }\end{array}$ & $P_{\mathrm{K}+} / P_{\mathrm{Na}+}$ & $P_{\mathrm{Li}+} / P_{\mathrm{Na}+}$ & $P_{\mathrm{Cs}+} / P_{\mathrm{Na}+}$ & $P_{\mathrm{Ca} 2+} / P_{\mathrm{Na}+}$ \\
\hline \multirow[t]{3}{*}{ LT } & \multirow[t]{3}{*}{$10 \sim 20$} & \multirow[t]{3}{*}{60.6} & $51.0 \pm 0.6$ & $761 / 2962^{b}$ & 1.76 & 0.92 & 1.03 & 0.37 \\
\hline & & & & & $14.2 \pm 3.3^{c}$ & $2.1 \pm 1.2$ & $-0.9 \pm 2.1$ & $0.8 \pm 0.8$ \\
\hline & & & $(n=13)$ & $(25.7 \%)$ & (13) & (4) & (8) & (5) \\
\hline \multirow[t]{3}{*}{ HT } & \multirow[t]{3}{*}{$>60$} & \multirow[t]{3}{*}{83.1} & $13.7 \pm 0.3$ & $700 / 2962^{b}$ & 1.43 & 1.06 & 1.13 & 0.42 \\
\hline & & & & & $-9.1 \pm 1.6^{c}$ & $-1.6 \pm 0.9$ & $-3.3 \pm 2.0$ & $2.4 \pm 0.02$ \\
\hline & & & $(n=11)$ & $(23.6 \%)$ & $(5)$ & (4) & (5) & (3) \\
\hline
\end{tabular}

\footnotetext{
${ }^{a}$ Average conductance of inside-out patches with holding potential of $-60 \mathrm{mV}$.

${ }^{b}$ Seventy-one patches containing both LT and HT channels are included.

${ }^{c}$ Represents reversal potentials in millivolts.

Numbers in the parentheses denote the number of experiments.
}

most frequently $(25.7 \%)$ (Table 1 ) and displayed the largest current amplitude of the MS channels in the cultured sensory neurons. When the amplitude of the channel currents was measured in cell-attached patches, the mean current amplitude of LT was found to be $-3.50 \pm 0.06 \mathrm{pA}(n=5)$ at $-60 \mathrm{mV}$ of holding potential.

Another type of MS channel was activated only by greater negative pressures than $-60 \mathrm{mmHg}$ (Fig. $2 \mathrm{~B}$ ), thus tentatively called a high-threshold (HT) MS channel. Unlike the LT channel, the HT MS channel showed small current amplitude (Fig. 2B). In cell-attached patches, the average current amplitude was $-0.9 \pm$ $0.04 \mathrm{pA}(n=5)$ at $-60 \mathrm{mV}$ of holding potential. This channel was also frequently observed in $23.6 \%$ of the total number of patches tested (Table 1). In contrast to the LT MS channel, the HT channel rarely showed residual activity when suction was removed. Furthermore, the HT MS channels were not activated by positive pressures up to $+80 \mathrm{mmHg}$.

\section{Pressure-response relationship}

The two types of channels exhibited a pressure-response relationship, but with different sensitivities (Fig. 2C). To obtain the pressure-response relationships of MS channels, negative pressures ranging from 0 to $-110 \mathrm{mmHg}$ were plotted against the channel activity of the MS channels. Membrane patches could not sustain greater negative pressures than $-110 \mathrm{mmHg}$. Relative channel activity $\left(N P_{\mathrm{o}} / N P_{\max }\right)$ at each pressure was fitted by a nonlinear regression to a Boltzmann distribution. The channel activity at each pressure was normalized to the maximum channel activity: $N P_{\mathrm{o}} / N P_{\text {max }}=1 /\left\{1+\exp \left(\left(p_{1 / 2}-p\right) / \alpha\right)\right\}$, where $N$ is the number of functional MS channels in the patch, $P_{\max }$ is the maximum probability of channel opening, $p$ is the suction pressure, $p_{1 / 2}$ is the suction pressure at which the open probability is 0.5 , and $\alpha$, sensitivity to the suction pressure, represents the pressure change required to cause an $e$-fold increase in the relative channel activity (Kim et al., 1995; Marchenko and Sage, 1997). As shown in Figure $2 C$, the half-maximal pressures, $p_{1 / 2}$, of LT and HT MS channels were $60.6 \pm 1.2(n=9)$ and $83.1 \pm 2.4$ mmHg $(n=9)$, respectively. The sensitivities $(\alpha)$ of LT and HT channels to negative pressures were $8.4 \pm 1.8$ and $4.3 \pm 0.9$ $\mathrm{mmHg}$, respectively. An interesting feature of these MS channels was that the maximal channel activity of the HT channel was much greater than that of the LT channels. For example, the near maximal, saturating channel activities of LT and HT MS channels at $-100 \mathrm{mmHg}$ were $0.21 \pm 0.05(n=9)$ and $0.94 \pm 0.09(n=9)$, respectively (see Fig. 6).

\section{Current-voltage relationship}

To determine the $I-V$ relationships of the two MS channels, membrane potentials were changed from -100 to $+100 \mathrm{mV}$ in 20 $\mathrm{mV}$ increments after forming inside-out patches. Constant negative pressures were applied to the membrane patches to activate the MS channels $(-60 \mathrm{mmHg}$ for LT channels and $-80 \mathrm{mmHg}$ for HT channels). The current amplitude of each channel was measured at each membrane potential in symmetric $140 \mathrm{~mm} \mathrm{Na}^{+}$ solution. The mean amplitudes were plotted as a function of the membrane potential. As shown in Figure 3, $A$ and $B$, the mean amplitudes of LT channels in the symmetrical solution were $-3.1 \pm 0.04$ and $+6.5 \pm 0.35 \mathrm{pA}$ at $E_{\text {hold }}=-60$ and $+60 \mathrm{mV}$, respectively $(n=13)$. Thus, the slope conductances of LT MS channels were $51.0 \pm 0.6$ and $108.3 \pm 5.9 \mathrm{pS}$ at $E_{\text {hold }}=-60$ and $+60 \mathrm{mV}$, respectively $(n=13)$, indicating that the single-channel currents were outwardly rectifying. In contrast, the HT MS channel exhibited a much smaller slope conductance with a nearly linear current-voltage relationship in the symmetrical solution. The slope conductances of HT MS channels were $13.7 \pm 0.3$ and $16.3 \pm 0.5 \mathrm{pS}$ at -60 and $+60 \mathrm{mV}$, respectively $(n=11)$ (Fig. 3A,B).

\section{Channel kinetics}

Histograms of open or closed-time durations of both MS channels activated by suction pressures were best fitted with two exponential functions (Fig. 3C). Therefore, both channels exhibited short and long openings and closings. Negative pressure of $-20 \mathrm{mmHg}$ activated LT MS channels with open time constants of $0.12 \pm 0.01$ $\left(\tau_{\mathrm{O} 1}, n=5\right)$ and $0.82 \pm 0.09 \mathrm{msec}\left(\tau_{\mathrm{O} 2}\right)$ and with closed time constants of $0.52 \pm 0.06\left(\tau_{\mathrm{C} 1}\right)$ and $14.76 \pm 1.01 \mathrm{msec}\left(\tau_{\mathrm{C} 2}\right)$. When negative pressure of $-80 \mathrm{mmHg}$ was applied to the same channels, the duration of short openings increased significantly $\left(\tau_{\mathrm{O} 1}=\right.$ $0.16 \pm 0.01 \mathrm{msec} ; p<0.05 ; n=5)$, but not that of long openings $\left(\tau_{\mathrm{O} 2}=0.93 \pm 0.06 \mathrm{msec}\right)$. In contrast, at $-80 \mathrm{mmHg}$, the duration of long closings, but not short closings $\left(\tau_{\mathrm{C} 1}=0.38 \pm 0.06 \mathrm{msec}\right.$; $n=5)$, decreased significantly $\left(\tau_{\mathrm{C} 2}=5.82 \pm 0.63 \mathrm{msec} ; p<\right.$ 0.001). Similarly, negative pressure of $-60 \mathrm{mmHg}$ activated HT MS channels with $\tau_{\mathrm{O} 1}$ and $\tau_{\mathrm{O} 2}$ of $0.11 \pm 0.01$ and $0.97 \pm 0.19 \mathrm{msec}$ $(n=5)$, respectively, and with $\tau_{\mathrm{C} 1}$ and $\tau_{\mathrm{C} 2}$ of $0.34 \pm 0.02$ and $5.45 \pm 0.41 \mathrm{msec}$, respectively. When the negative pressure was changed to $-100 \mathrm{mmHg}, \tau_{\mathrm{O} 2}$, but not $\tau_{\mathrm{O} 1}$, increased significantly to $1.37 \pm 0.25 \mathrm{msec}(p<0.001 ; n=5)$. In contrast, both $\tau_{\mathrm{C} 1}$ and $\tau_{\mathrm{C} 2}$ decreased significantly $(0.13 \pm 0.01$ and $0.82 \pm 0.16 \mathrm{msec}$, respectively; $p<0.001 ; n=5)$ at $-100 \mathrm{mmHg}$. Therefore, greater 
A

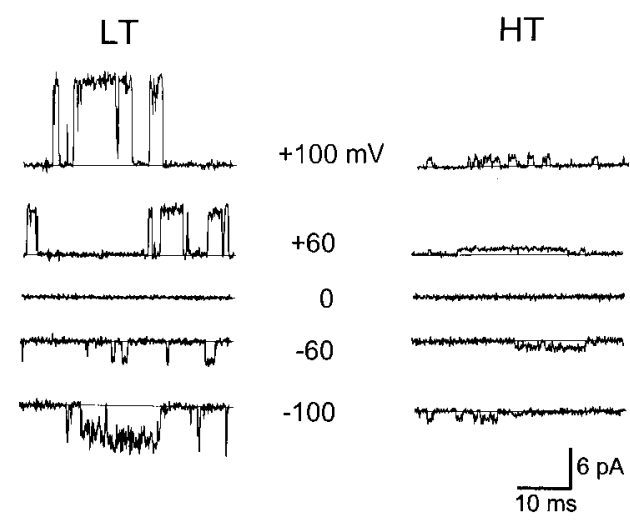

B

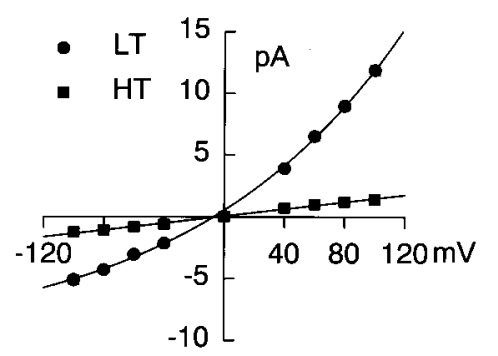

C

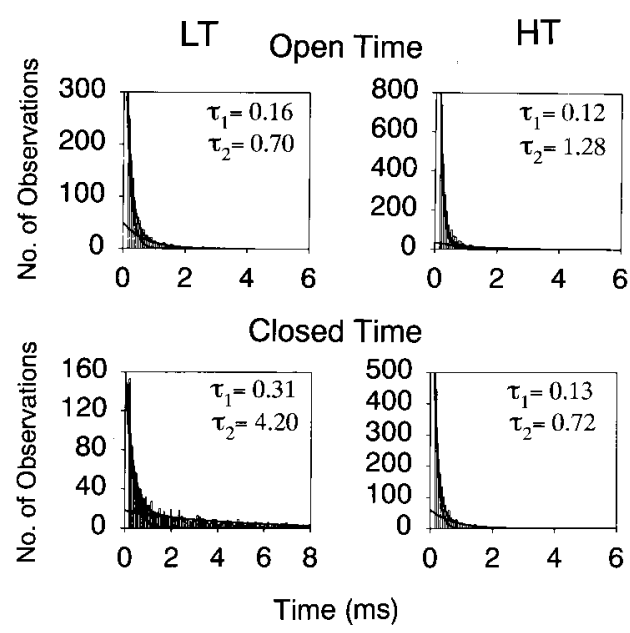

Figure 3. Current-voltage relationships and kinetics of LT and HT MS channels. $A$, Traces in the expanded time scale of single-channel currents of the two MS channels held at different membrane potentials. Suction pressures of -60 and $-80 \mathrm{mmHg}$ were delivered to pipettes of inside-out patches to activate the LT and HT MS channels, respectively. $B$, Currentvoltage relationships of single-channel currents. LT, Filled circle $(n=13)$; HT, filled square $(n=11)$. To obtain the current-voltage relationship of LT channels, each data point was fitted to a single exponential equation. Bars represent SEM. The error bars are so small that they are included by the circles or squares. $C$, Open and closed time histograms of LT and HT MS channels. LT and HT channels were activated by -80 and -100 $\mathrm{mmHg}$, respectively. The histograms of open and closed time durations of the two channels were best fitted by two exponential functions.

pressures increased the channel activities of both MS channels largely by decreasing the duration of long closings.

\section{Ion selectivity}

To determine whether the two MS channels were permeable to cations or anions, $140 \mathrm{mM}$ of $\mathrm{Na}^{+}$in bath solution was replaced by $N$-methyl-D-glucamine in inside-out patches under constant pressures $(-60$ and $-80 \mathrm{mmHg}$ for LT and HT channels, respectively). When $140 \mathrm{~mm} \mathrm{~N}$-methyl-D-glucamine in the bath was substituted for $140 \mathrm{mM} \mathrm{Na}^{+}$, inward currents with similar ampli-
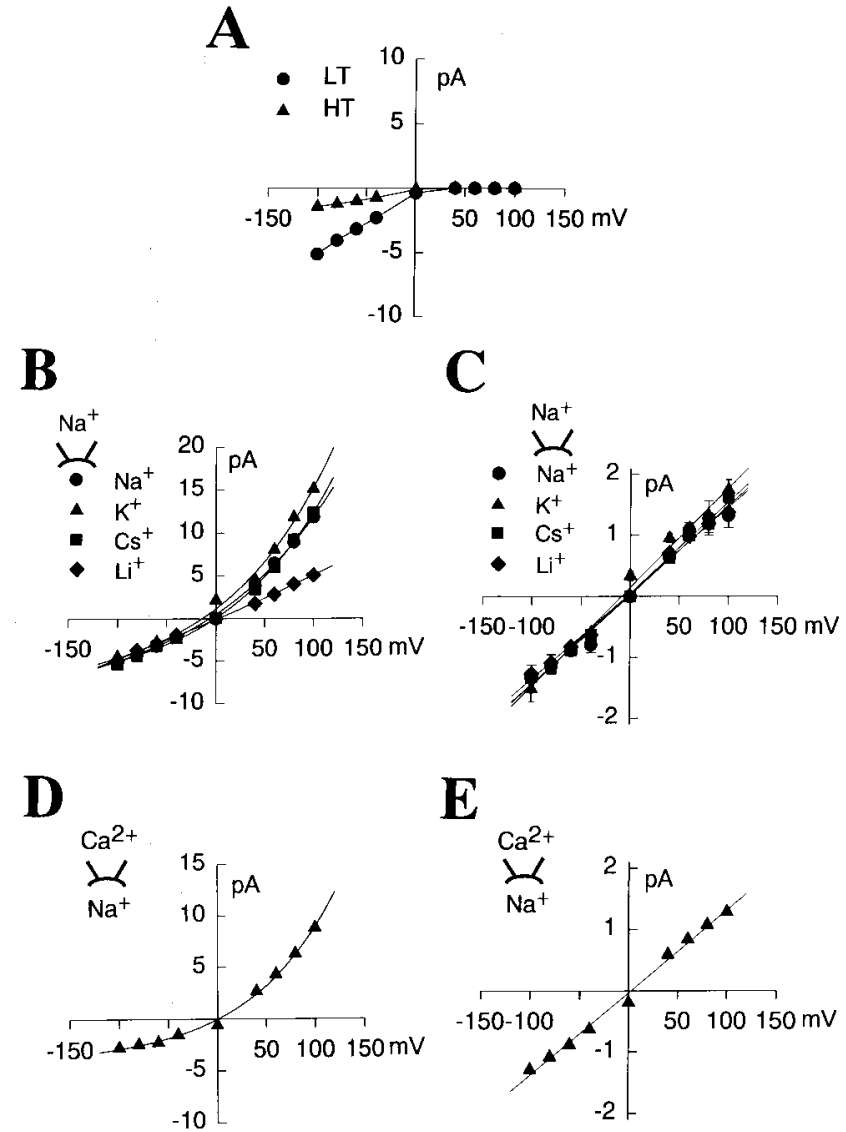

Figure 4. Ion selectivity of LT and HT channels. $A$, The $N$-methyl-Dglucamine substitution. No outward channel currents were observed for the two types of MS channels when the $140 \mathrm{mM} \mathrm{Na}^{+}$bath solution was replaced by a solution containing $140 \mathrm{~mm} N$-methyl-D-glucamine $(n=3$ for each MS channel). $B, C$, Cation selectivity of LT $(B)$ and HT (C) MS channels. Current-voltage relationships of each type of MS channels were obtained after the symmetrical $140 \mathrm{~mm} \mathrm{Na}{ }^{+}$bath solution of inside-out patches was replaced by solutions containing equimolar $\mathrm{K}^{+}, \mathrm{Cs}^{+}$, or $\mathrm{Li}^{+}$. The $I-V$ relationships of the MS channels in the symmetrical $140 \mathrm{~mm} \mathrm{Na}^{+}$ salt condition are identical to those shown in Figure 3. D, E, Permeability of LT $(D)$ and HT $(E)$ MS channels to $\mathrm{Ca}^{2+}$. Current-voltage relationships were obtained from inside-out patches that contained $100 \mathrm{mM} \mathrm{Ca}^{2+}$ in the pipette solution and $140 \mathrm{~mm} \mathrm{Na}{ }^{+}$in the bath solution.

tudes to those observed for the two MS channels in the control bath solution were observed ( $n=3$ for each LT and HT MS channel) when the membrane potential was held at $-40 \mathrm{mV}$ or lower. However, no detectable outward currents were observed for either type of MS channels when the membrane potential was held at $+40 \mathrm{mV}$ or greater (Fig. $4 A$ ). These results indicate that the two MS channels are permeable to cations but not to anions.

We further determined the ion selectivity of the channels among cations, by testing changes in reversal potential in insideout patches under bi-ionic salt conditions. Current amplitudes, at various holding potentials, were measured before and after the bath $\mathrm{Na}^{+}$solution was replaced with equimolar $\mathrm{Li}^{+}, \mathrm{K}^{+}$, or $\mathrm{Cs}^{+}$. As shown in Figure 4, $B$ and $C$, the replacement of $\mathrm{Na}^{+}$with other monovalent cations did not shift the reversal potentials of the MS channels from $0 \mathrm{mV}$, indicating that the two types of MS channels could discriminate these monovalent cations poorly. Selectivity over $\mathrm{Ca}^{2+}$ was also assessed by measuring the reversal potential when $140 \mathrm{mM} \mathrm{Na}^{+}$in the pipette was replaced by 100 $\mathrm{mM} \mathrm{Ca}^{2+}$ (Fig. 4D,E). In the bi-ionic system $\left(100 \mathrm{~mm}\left[\mathrm{Ca}^{2+}\right]_{0} /\right.$ 


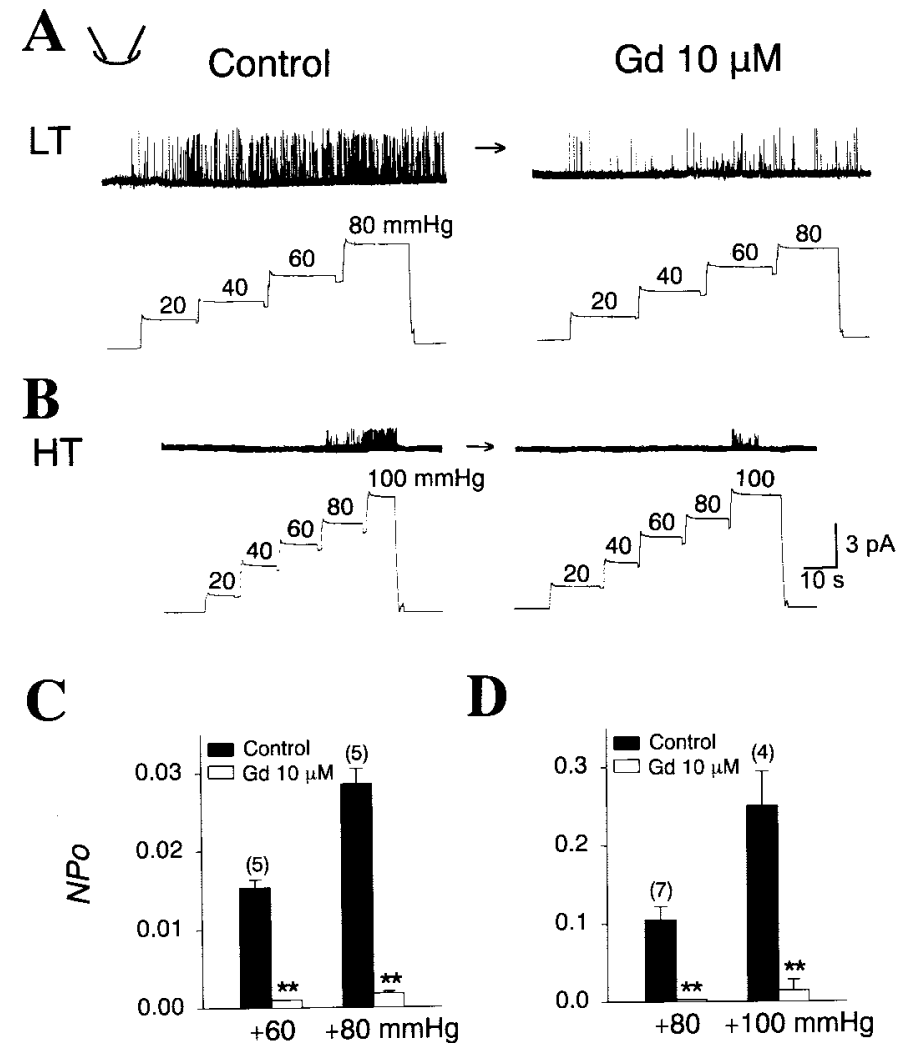

Figure 5. Block of MS channels by Gd. $A, B$, Example traces depicting the effects of $10 \mu \mathrm{M}$ Gd on activities of LT $(A)$ and HT $(B)$ MS channels in outside-out patches. The membrane potential was held at $-60 \mathrm{mV}$ throughout the experiments. $C, D$, Summaries of the effects of $\mathrm{Gd}$ on activities of LT $(C)$ and HT $(D)$ MS channels. Numbers on the bars represent the number of experiments. ${ }^{*} p<0.01$

$\left.140 \mathrm{~mm}\left[\mathrm{Na}^{+}\right]_{\mathrm{i}}\right)$, the reversal potentials of the LT and HT MS channels were $0.78 \pm 0.8(n=5)$ and $2.38 \pm 0.02 \mathrm{mV}(n=3)$, respectively, indicating that the MS channels are also permeable to $\mathrm{Ca}^{2+}$. The permeability ratios $\left(P_{\text {cation }} / P_{\mathrm{Na}}\right)$ for both LT and HT channels for $\mathrm{Na}^{+}$and monovalent cations or $\mathrm{Ca}^{2+}$ were calculated from the modified constant-field equation (Fatt and Ginsborg, 1958) and are shown in Table 1.

\section{Block by gadolinium}

The gadolinium ion $\left(\mathrm{Gd}^{3+}\right)$ has been reported to block various types of MS channels (Yang and Sachs, 1989; Hamill and McBride, 1996). Thus, we investigated whether $\mathrm{Gd}^{3+}$, the nonselective blocker of many MS channels, could block the LT and HT MS channels present in sensory neurons. To apply $\mathrm{Gd}^{3+}$ to the extracellular surface of the channels, outside-out patches were formed. Positive pressures ranging from +60 to +100 $\mathrm{mmHg}$ were delivered to the pipettes of outside-out patches before and after $10 \mu \mathrm{M} \mathrm{Gd}^{3+}$ was applied. Because EGTA, which chelates $\mathrm{Ca}^{2+}$ also reduces free $\mathrm{Gd}^{3+}$ (Boland et al., 1991; Hamill and McBride, 1996; Caldwell et al., 1998), EGTA was removed from both the control and the $\mathrm{Gd}^{3+}$-containing solution. Bath application of the $\mathrm{Gd}^{3+}$ greatly blocked activity of the LT channel (Fig. $5 A, C$ ) at +60 and $+80 \mathrm{mmHg}$ by $93.5 \pm 0.6$ and $92.4 \pm 0.4 \%$, respectively. Activity of the HT MS channel was also blocked by $\mathrm{Gd}^{3+}$, as shown in Figure $5, B$ and $D: 10 \mu \mathrm{M}$ $\mathrm{Gd}^{3+}$ reduced activity of the $\mathrm{HT}$ channel activated by +80 and $+100 \mathrm{mmHg}$ by $97.9 \pm 0.5$ and $92.0 \pm 8.6 \%$, respectively.

\section{Effect of the disruption of cytoskeletal elements}

Many types of MS channels are often sensitive to conformational changes in cytoskeletons (Small and Morris, 1994; Hamill and McBride, 1996; Maingret et al., 1999). Thus, the integrity of cytoskeletal elements near the cell membrane appears to be important for the activation of MS channels. Therefore, we examined whether the MS channels of DRG neurons were affected by cytoskeletal disruption in the cell. Colchicine and cytochalasin $\mathrm{D}$ are known to disrupt the assembly of cytoskeletons and are considered to be cytoskeleton-disrupting agents (Cooper, 1987; Sadoshima et al., 1992). To determine the effects of colchicine or cytochalasin D on the MS channels, channel activities activated by various pressures were obtained and compared before and after treatment with cytoskeleton-disrupting agents. Repeated applications with $20 \mathrm{~min}$ intervals of negative-pressures up to $-110 \mathrm{mmHg}$ did not change the overall pressure-activity relationships of the LT and HT MS channels in cell-attached patches (Fig. 6C).

In contrast, the application of $10 \mu \mathrm{M}$ of cytochalasin $\mathrm{D}$ to the bath of cell-attached patches for $\sim 20$ min significantly suppressed the channel activities of LT and HT channels over the range of pressures tested (Fig. 6D). Cytochalasin D $(10 \mu \mathrm{M})$ significantly attenuated the maximal activity of LT and HT channels by $84.6 \pm$ $2.6(n=6 ; p<0.001)$ and $59.8 \pm 3.2 \%(n=7 ; p<0.001)$. A similar response pattern was observed after treatment with another cytoskeleton disrupter, colchicine. Colchicine $(500 \mu \mathrm{M})$ treatment reduced the maximal activities of the LT and HT channels significantly by $88.4 \pm 3.2(n=5 ; p<0.001)$ and $50.9 \pm$ $6.9 \%(n=6 ; p<0.001)$, respectively (Fig. $6 E)$. Treatments with colchicine and cytochalasin $\mathrm{D}$ shifted the pressure-activity curve of HT channels rightward, increasing $\mathrm{p}_{1 / 2}$ of HT channels significantly from $80.8 \pm 2.8$ to $91.4 \pm 3.3 \mathrm{mmHg}(n=6 ; p<0.05)$ and from $79.8 \pm 0.76$ to $87.7 \pm 2.03 \mathrm{mmHg}(n=7 ; p<0.01)$, respectively. The cytoskeletal disrupters, however, did not change the $p_{1 / 2}$ of LT channels.

\section{Effect of excision}

Because excision of the cell membrane often changes activity of certain MS channels (Marchenko and Sage, 1997; Maingret et al., 1999), we also examined the effect of excision on activity of the MS channels. Excision of the cell membrane from cell-attached patches to make inside-out patches greatly reduced the maximal current responses of the LT and HT channels. After forming inside-out patches, activity of LT MS channels at $-100 \mathrm{mmHg}$ reduced to $0.028 \pm 0.005$ by $87.5 \pm$ $4.7 \%(n=5)$ from that measured when cell-attached patches were formed $(0.21 \pm 0.005 ; n=5)$. In HT MS channels, excision of the patch membrane reduced the channel activity activated by $-110 \mathrm{mmHg}$ from $1.02 \pm 0.09$ to $0.42 \pm 0.07$ $(57.8 \pm 7.5 \%$ reduction; $n=4)$.

\section{Effect of amiloride and arachidonic acid}

A diuretic, amiloride, and its analogs are known to block many MS channels, including MS currents in sensory neurons and epithelial sodium channels (Lane et al., 1991; Awayda et al., 1995; Hamill and McBride, 1996; McCarter et al., 1999). Thus, it appeared likely that amiloride would block the activity of the MS channels present in sensory neurons. However, the application of amiloride up to $200 \mu \mathrm{M}$ in the bath of outside-out patches $(n=5)$ or inside-out patches $(n=6)$ did not affect activities of LT and HT MS channels. Arachidonic acid and other unsaturated fatty acids are known to activate certain types of mechanically- 

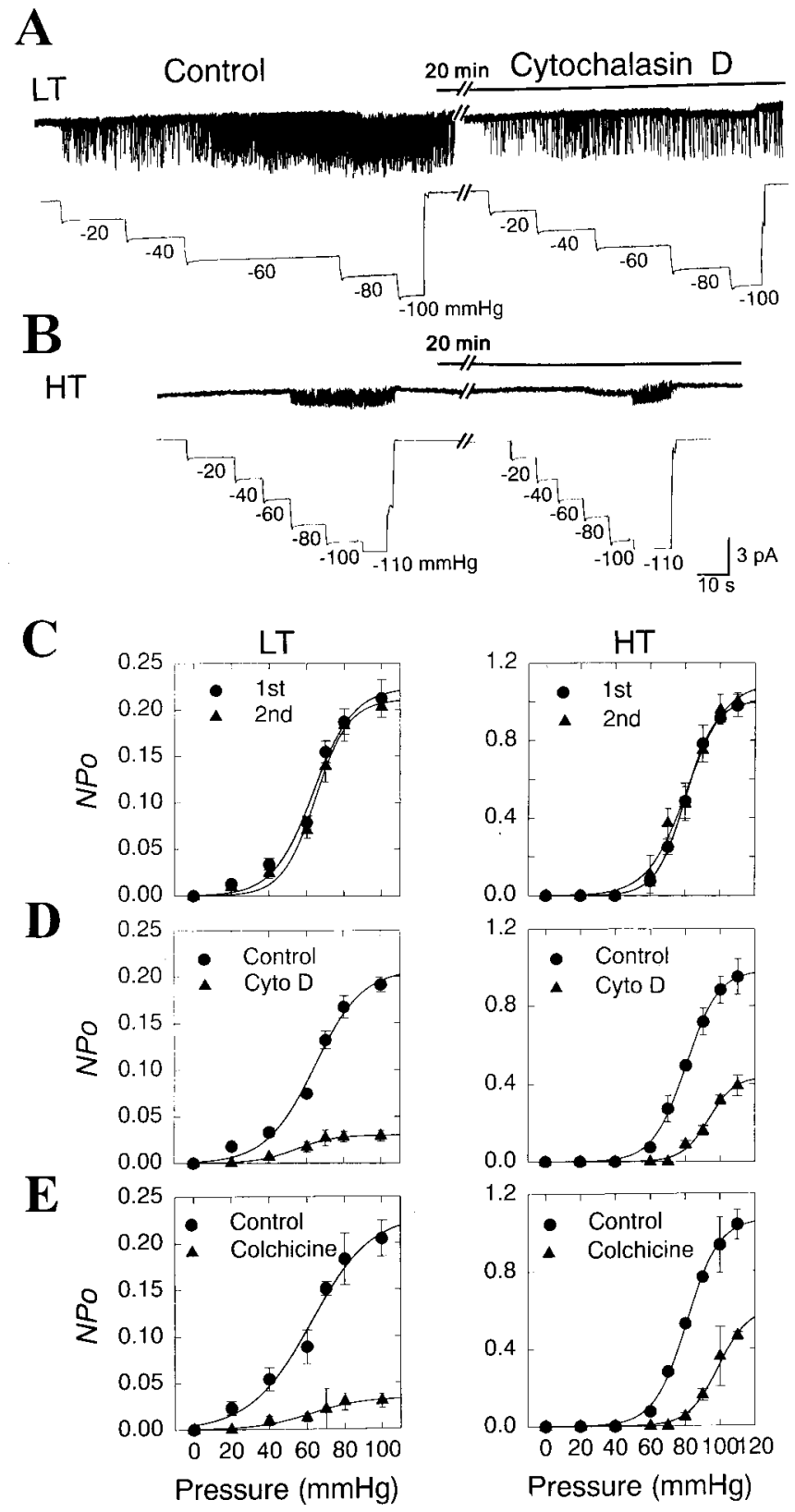

Figure 6. Inhibition of activities of the LT and HT channels by cytoskeleton disrupters, cytochalasin $\mathrm{D}$, and colchicine. $A, B$, Example traces of the effect of cytochalasin D on activities of LT $(A)$ and HT $(B)$ MS channels. Negative pressures were applied to patch pipettes to activate the MS channels after forming cell-attached patches. The cell-attached patches were incubated with $10 \mu \mathrm{M}$ cytochalasin $\mathrm{D}$ for $\sim 20 \mathrm{~min}$. The negative pressures were repeated after the cytochalasin $\mathrm{D}$ application. $C$, Summaries of the effects of repeated applications of suction pressures on the pressureactivity relationships of LT $(n=4-6)$ and HT $(n=4-7)$ MS channels. Note that repeated applications of suction pressures do not change the overall responses of the MS channels to pressures. $D$, Summaries of the effects of $10 \mu \mathrm{M}$ cytochalasin D on the pressure responses of LT $(n=4-6)$ and HT $(n=3-7)$ MS channels. E, Summaries of the effects of $500 \mu \mathrm{M}$ colchicine on the pressure responses of LT $(n=4-5)$ and HT $(n=3-6)$ MS channels.

activated $\mathrm{K}^{+}$channels (Kim et al., 1995; Maingret et al., 1999). To test whether arachidonic acid affects the two types of MS channels, arachidonic acid was applied to the bath of inside-out patches containing each type of the MS channels. When applied to the bath of inside-out patches, $10 \mu \mathrm{M}$ of arachidonic acid failed to change the activities of LT or HT MS channels ( $n=4$ for each type of the MS channels).

\section{Effect of prostaglandin $E_{2}$}

A unique action of prostaglandin $\mathrm{E}_{2}\left(\mathrm{PGE}_{2}\right)$ on the pain sensory system is accounted for by its ability to cause hyperalgesia or sensitize nociceptive sensory neurons to mechanical stimuli, possibly via the protein kinase A pathway (Martin et al., 1987; Taiwo et al., 1989; Taiwo and Levine, 1991; Ouseph et al., 1995; Cunha et al., 1999; Chen et al., 1999). Thus, we examined whether $\mathrm{PGE}_{2}$ sensitized the MS channels present in sensory neurons. To determine the effects of $\mathrm{PGE}_{2}$ on the activities of the LT and HT channels, $10 \mu \mathrm{M} \mathrm{PGE}_{2}$ was administered to the bath of cellattached patches containing the MS channels for 5 min before a second series of negative-pressures were applied. As shown above (Fig. 6C), under control conditions repeated applications of suction pressures in cell-attached patches did not change the overall pattern of pressure-activity relationships of the MS channels. However, pretreatment of $10 \mu \mathrm{M} \mathrm{PGE}_{2}$ for $5 \mathrm{~min}$ shifted the pressure-activity curve to the left, decreasing significantly the mechanical threshold (60 vs $40 \mathrm{mmHg}$ ) and the $\mathrm{p}_{1 / 2}(81.6 \pm 5.0 \mathrm{vs}$ $56.9 \pm 2.3 \mathrm{mmHg} ; p<0.001 ; n=14$ ) of the HT MS channel (Fig. $7 A$ ). The $\mathrm{PGE}_{2}$-induced sensitization of the HT MS channels was presumably mediated by the cAMP-dependent protein kinase pathway, because the pretreatment of sensory neurons with $\mathrm{H}-89$ $(10 \mu \mathrm{M})$, a membrane-permeable inhibitor of protein kinase A, completely blocked the sensitization of the channel by $\mathrm{PGE}_{2}$ (Fig. $7 B, C)$. Furthermore, application of $100 \mu \mathrm{M}$ dibutyryl cAMP, a membrane-permeable analog of cAMP, also shifted the pressureactivity relationship to the left (Fig. $7 D)$, reducing $\mathrm{p}_{1 / 2}$ from $83.6 \pm 5.3$ to $59.1 \pm 2.9 \mathrm{mmHg}(p<0.001 ; n=10)$. In contrast to the HT channels, however, $\mathrm{PGE}_{2}$ failed to change the overall pattern of the pressure-activity relationship of LT channels $\left(\mathrm{p}_{1 / 2}=62.6 \pm 2.0\right.$ vs $\left.59.0 \pm 2.1 \mathrm{mmHg} ; n=6\right)$.

\section{Cell-size distribution}

The size of sensory neurons is one way of determining their sensory modalities, such as touch or pain (Winkelmann, 1986; Willis and Coggeshall, 1991). Therefore, we measured the diameter of the soma of cultured DRG neurons in which MS channels were detected. Figure 8 shows distribution of cultured sensory neurons having each type of MS channel. Proportions of 1461 neurons that elicited LT $(n=761)$ and HT $(n=700)$ singlechannel currents were constructed according to neuron size. As shown in Figure 8, the LT and HT MS channels were found mainly in small to medium-sized DRG neurons, whereas, LT and HT MS channels were rarely found in relatively large $(>30 \mu \mathrm{m}$ in diameter) sensory neurons. We tested the presence of the MS single-channel currents in 190 additional cell-attached patches from 190 neurons having diameters $>30 \mu \mathrm{m}$ up to $40 \mu \mathrm{m}$, none of which elicited the MS single-channel currents. The distribution of cells having HT MS channel currents was skewed (88\%) toward smaller cells with diameters of $10-17.5 \mu \mathrm{m}$ and significantly $(p<$ 0.0001) different from that of cells having LT channels. LT MS channels appeared to be distributed throughout cells with diameters of $10-30 \mu \mathrm{m}$ : only $48 \%$ of cells with diameters of $10-17.5$ $\mu \mathrm{m}$ elicited the LT MS channel currents.

Figure 8 also depicts the cell size distribution of sensory neurons eliciting whole-cell currents. Consistent with another report (Takahashi and Gotoh, 2000), cells eliciting MS whole-cell currents had a diameter $>20 \mu \mathrm{m}$. The distribution of cells eliciting 

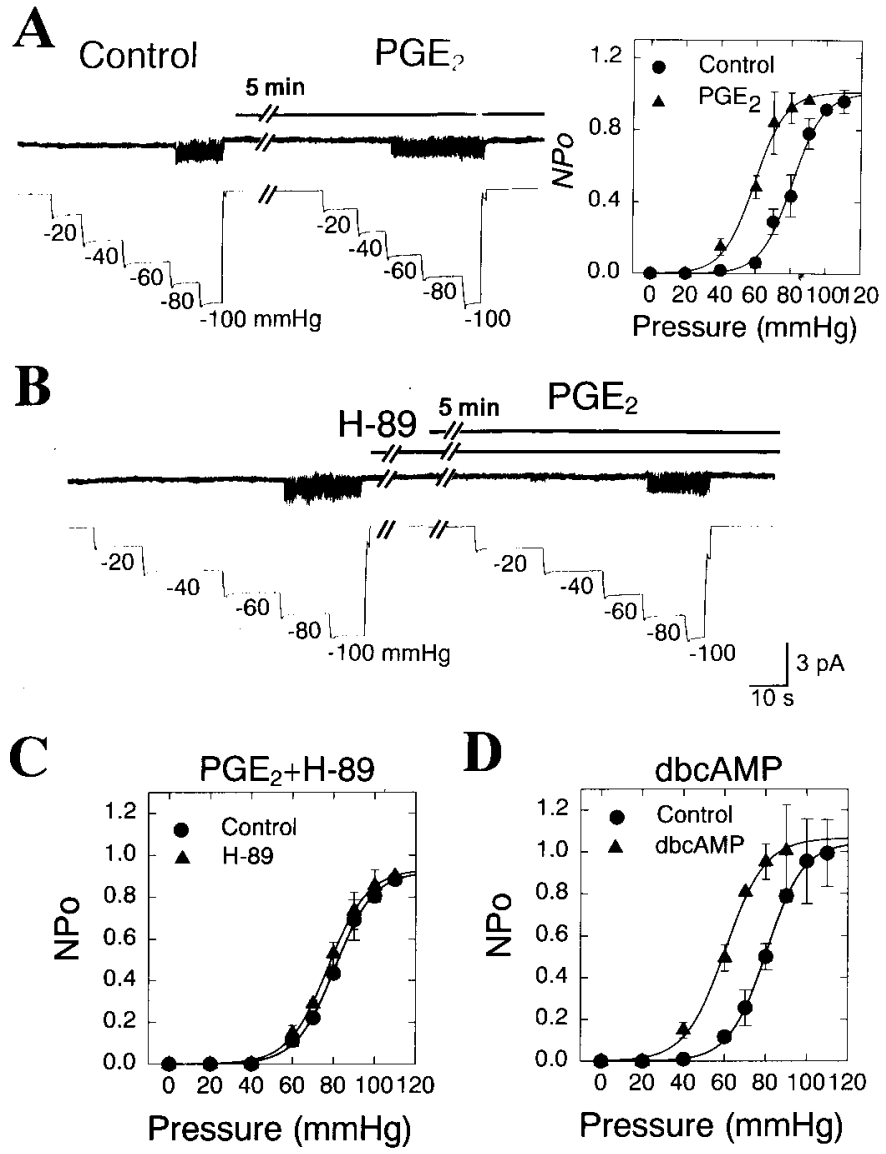

Figure 7. Sensitization of HT MS channel by $\mathrm{PGE}_{2}$ via the protein kinase A pathway. $A$, Negative pressures were repeated in cell-attached patches at a holding potential of $-60 \mathrm{mV}$. Before and during the second application of suction pressures, the cell-attached patches of sensory neurons were incubated with $10 \mu \mathrm{M} \mathrm{PGE}_{2}$ for $\sim 5 \mathrm{~min}$. Right, The pressure-activity relationships of HT MS channels before (circle; $n=$ $6-14$ ) and after $\mathrm{PGE}_{2}$ (triangle; $n=6-14$ ) treatment. Channel activity $\left(N P_{\mathrm{o}}\right)$ at each pressure was fitted to the Boltzmann distribution described in the text. Bars represent SEM. B, Block of the $\mathrm{PGE}_{2}$-induced sensitization of HT channels by H-89, an inhibitor of protein kinase A. H-89 (10 $\mu \mathrm{M})$ was incubated before and during $\mathrm{PGE}_{2}$ application. $C$, A summary of the effect of coapplication of $\mathrm{H}-89$ and $\mathrm{PGE}_{2}$ on the pressure-response relationship of HT MS channels. Control (circle; $n=5-10$ ), after H-89 treatment (triangle; $n=5-10$ ). $D$, A summary of the effect of the application of dibutyryl cAMP $(d b c A M P)$, a soluble cAMP analog, on the pressure-response relationship of HT MS channels. Control (circle; $n=$ 5-10), after dbcAMP treatment (triangle; $n=5-10$ ).

MS whole-cell currents overlapped substantially with that of LT MS channels. However, analysis with a Fisher's exact test revealed that distribution of cells eliciting the whole-cell currents was different from those of cells having LT $(p<0.0002)$ and HT $(p<0.0002)$ channel currents.

\section{DISCUSSION}

DRG neurons are primary afferent neurons that carry sensory signals from the skin, muscles, joints, and visceral organs to the spinal cord. The nerve endings of DRG neurons possess a variety of sensory receptors activated by mechanical, thermal, chemical, and noxious stimuli. Various mechanical, thermal, or noxious stimuli are known to generate action potentials at peripheral nerve endings of the DRG neurons (Winkelmann, 1986; Willis and Coggeshall, 1991). Ion channels thought to be responsible for somatosensory transduction have been identified in sensory neu-

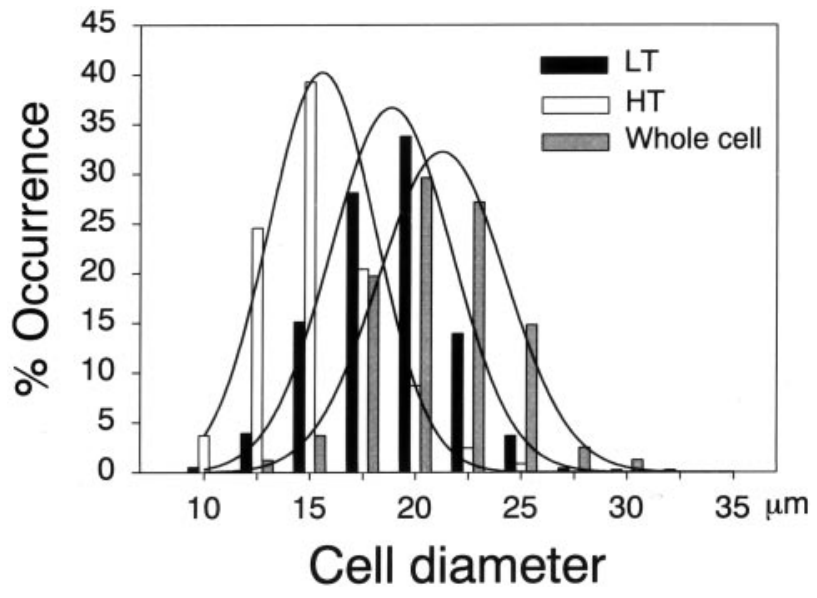

Figure 8. Cell-size proportions of cultured sensory neurons eliciting each type of MS channel or whole-cell currents in cultured DRG neurons.

rons, and some of their molecular species have now been cloned (Caterina et al., 1997; Caterina and Julius, 1999). Although ion channels that account for the neural signals of various sensory modalities are now known, little is known of their channels for mechanosensation. In the present study, we identified two novel cationic channels in cultured sensory neurons that were activated by mechanical stimulus. The two MS channels appeared distinct from other MS channels found in various cell types or newly cloned channels because of their difference in biophysical properties such as their conductance, ion selectivity, or currentvoltage relationship as well as sensitivity to pressure (Hamill and McBride, 1996; Hamill and Martinac, 2001). Because DRG neurons are neural substrates for mediating somatic and visceral sensation as well as proprioception, the two types of MS channels in sensory neurons implicate in mechanosensation, proprioception or possibly pain caused by noxious mechanical stimuli.

Pressures applied to membrane patches or whole cells would develop different membrane tensions that would be more relevant stimuli than pressures. The membrane tension $(T)$ caused by pressure can be calculated from Laplace's Law:

$$
T=\operatorname{Pr} / 2
$$

where $P$ is the pressure applied to a patch, and $r$ is the radius of the curvature of a membrane patch (Guharay and Sachs, 1984). If the geometry of the patch is assumed to be hemispheric with a diameter equal to that of the pipette $(1.4 \mu \mathrm{m})$, pressures of $10-110 \mathrm{mmHg}$ applied to the membrane patch would produce tensions of $0.47-5.1 \mathrm{mN} / \mathrm{m}$. However, the geometry of a patch in a glass pipette is known to be much flatter than a hemisphere, having a greater radius than that of a hemisphere (Sokabe et al., 1991; Opsahl and Webb, 1994; Akinlaja and Sachs, 1998). Therefore, it is highly likely that the actual tensions of the patch caused by the pressures would be greater than the assumed tensions. Furthermore, the cell membrane consists of lipid bilayer and cytoskeletons underlying the lipid bilayer (Hamill and McBride, 1997; Hamill and Martinac, 2001). Pressures applied to the patch membrane would act on the lipid bilayer and the cytoskeletons (Hamill and McBride, 1997). Therefore, the assumption that pressures cause the estimated tensions along the lipid bilayer might be oversimplified.

Recently, nonselective cation currents activated by stretch or pressure applied to whole cells was reported in cultured DRG 
neurons (McCarter et al., 1999; Takahashi and Gotoh, 2000). The MS whole-cell currents were generally consistent with the inward whole-cell currents observed in the present study. Because membrane geometry of whole cells is different from those of membrane patches, it is difficult to compare pressure sensitivities of the two types of MS channels with those of the whole-cell currents. However, some aspects of the MS whole-cell current possess similarities with the LT and HT MS channels. First, the two MS channels were the most frequently encountered MS channels in sensory neurons. Second, the whole-cell and the MS singlechannel currents were cationic. Therefore, the two MS channels would represent in part the macroscopic currents activated by pressures. However, we cannot exclude the possible presence of other MS channels in sensory neurons that contribute to the MS whole-cell currents, partly because distributions of neurons eliciting the two MS single-channel currents did not overlap with that of neurons having the MS whole-cell currents (Fig. 8).

Several lines of evidence in the present study suggest that HT MS channels are related to mechanosensation in a noxious range. First, HT channels were observed mainly in small DRG neurons and rarely found in large cells $(>30 \mu \mathrm{m}$ in diameter). Direct measurements of cell body size and the conduction velocity of primary afferent fibers demonstrate that most of the large sensory neurons are low-threshold mechanoreceptors and detect innocuous stimuli, whereas most smaller neurons are nociceptors, which detect noxious mechanical, thermal, or chemical stimuli (Harper and Lawson, 1985; Winkelmann, 1986; Willis and Coggeshall, 1991; Perl, 1996). Thus, the presence of the HT channels in small DRG neurons indicates their possible role in the mediation of mechanical pain in nociceptive neurons. Second, the majority of HT channels were activated by pressures over $60 \mathrm{mmHg}$. This channel had the highest-pressure threshold found in sensory neurons. Furthermore, the channel was sensitized by $\mathrm{PGE}_{2}$. $\mathrm{PGE}_{2}$ released in response to tissue injury and inflammation is known to cause mechanical hyperalgesia and sensitize sensory neurons to mechanical stimuli specifically via the protein kinase A pathway (Martin et al., 1987; Schaible and Schmidt, 1988; Taiwo and Levine, 1988; Ouseph et al., 1995; Chen et al., 1999; Cunha et al., 1999). In the present study, $\mathrm{PGE}_{2}$ lowered the threshold of HT, but not that of LT MS channels. The sensitization of HT channels by $\mathrm{PGE}_{2}$ was mediated by the protein kinase A pathway (Fig. 7). Thus, our results indicate that the HT MS channel is a likely candidate for transducing mechanical stimuli to nociceptive neural signals.

Many MS channels in various cells are often coupled to the cytoskeleton (Hamill and Martinac, 2001). Thus, cytoskeletons may be an important factor for regulating MS channel function. Colchicine, an antimitotic drug that disrupts microtubules (Borgers et al., 1975), abolishes mechanotransduction in Caenorhabditis elegans (Chalfie and Thomson, 1982). The activity of TRAAK, a mammalian neuronal two-pore $\mathrm{K}^{+}$channel that is sensitive to mechanical stimulation, is enhanced by colchicine treatment (Maingret et al., 1999), and cytochalasin D increases the sensitivity of MS channels to stretch in chick skeletal muscle and in Lymnaea neurons (Guharay and Sachs, 1984; Small and Morris, 1994). Thus, MS channel activity appears to be dependent largely on the integrity of the cytoskeleton. In the present study, disruption of cytoskeletons by colchicine or cytochalasin D greatly reduced the activity of MS channels. In addition, although it is not clearly defined, excision of the cell membrane to make inside-out or outside-out patches is likely to affect the membranecytoskeleton interaction (Hamill and McBride, 1997; Marchenko and Sage, 1997; Maingret et al. 1999). We also observed that excision of the cell membrane greatly reduced the current responses to pressures. Especially, when outside-out patches were formed, a substantial portion of the membrane was pulled and re-annealed. After forming outside-out patches, however, the integrity of cytoskeleton was not lost completely because activities of MS channels remained (Fig. 5). Thus, unlike other MS channels, whose activity was enhanced after cytoskeletal disruption, cytoskeleton and associated proteins seem to be functionally connected to the MS channels in sensory neurons as positive regulators.

In summary, we report here on two distinct types of MS channels present in cultured sensory neurons. These cationic channels have different pressure thresholds as well as distinct biophysical properties. Thus, the channels may account in part for macroscopic MS currents observed in sensory neurons and subserve molecular transducers in sensory neurons for mechanosensations such as somatosensation or proprioception. Because the HT channels are present in small sensory neurons, activated only by high pressures, and sensitized by $\mathrm{PGE}_{2}$, the HT MS channels are also likely to be implicated in generation of nociceptive neural signals. However, the precise functional roles of the channels remain to be studied until molecular species for the channels are identified.

\section{REFERENCES}

Akinlaja J, Sachs F (1998) The breakdown of cell membranes by electrical and mechanical stress. Biophys J 75:247-254.

Awayda MS, Ismailov II, Berdiev BK, Benos DJ (1995) A cloned renal epithelial $\mathrm{Na}+$ channel protein displays stretch activation in planar lipid bilayers. Am J Physiol 268:C1450-C1459.

Boland LM, Brown TA, Dingledine R (1991) Gadolinium block of calcium channels: influence of bicarbonate. Brain Res 563:142-150.

Borgers M, De Nollin S, De Brabander M, Thienpont D (1975) Influence of the anthelmintic mebendazole on microtubules and intracellular organelle movement in nematode intestinal cells. Am J Vet Res 36:1153-1166.

Caldwell RA, Clemo HF, Baumgarten CM (1998) Using gadolinium to identify stretch-activated channels: technical considerations. Am J Physiol 275:C619-621.

Caterina MJ, Julius D (1999) Sense and specificity: a molecular identity for nociceptors. Curr Opin Neurobiol 9:525-530.

Caterina MJ, Schumacher MA, Tominaga M, Rosen TA, Levine JD, Julius D (1997) The capsaicin receptor: a heat-activated ion channel in the pain pathway. Nature 389:816-824.

Chalfie M, Thomson JN (1982) Structural and functional diversity in the neuronal microtubules of Caenorhabditis elegans. J Cell Biol 93:15-23.

Chen X, Tanner K, Levine JD (1999) Mechanical sensitization of cutaneous C-fiber nociceptors by prostaglandin E2 in the rat. Neurosci Lett 267:105-108.

Cooper JA (1987) Effects of cytochalasin and phalloidin on actin. J Cell Biol 105:1473-1478.

Cunha FQ, Teixeira MM, Ferreira SH (1999) Pharmacological modulation of secondary mediator systems-cyclic AMP and cyclic GMP-on inflammatory hyperalgesia. Br J Pharmacol 127:671-678.

Driscoll M, Chalfie M (1991) The mec-4 gene is a member of a family of Caenorhabditis elegans genes that can mutate to induce neuronal degeneration. Nature 349:588-593.

Fatt P, Ginsborg BL (1958) The ionic requirements for the production of action potentials in crustacean muscle fibers. J Physiol (Lond) 142:516-543.

Garcia-Anoveros J, Corey DP (1997) The molecules of mechanosensation. Annu Rev Physiol 20:567-594.

Gardner EP, Martin JH, Jessell TM (2000) The bodily senses. In: Principles of Neural Science (Kandel ER, Schwartz JH, Jessell TM, eds), pp 430-450. New York: McGraw Hill.

Guharay F, Sachs F (1984) Stretch-activated single ion channel currents in tissue-cultured embryonic chick skeletal muscle. J Physiol (Lond) 352:685-701.

Hamill OP, Martinac B (2001) Molecular basis of mechanotransduction in living cells. Physiol Rev 81:685-740.

Hamill OP, McBride Jr DW (1992) Rapid adaptation of single mechanosensitive channels in Xenopus oocytes. Proc Natl Acad Sci USA 89:7462-7466. 
Hamill OP, McBride Jr DW (1996) The pharmacology of mechanogated membrane ion channels. Pharmacol Rev 48:231-252.

Hamill OP, McBride Jr DW (1997) Induced membrane hypo/hypermechanosensitivity: a limitation of patch-clamp recording. Annu Rev Physiol 59:621-631.

Harper AA, Lawson SN (1985) Conduction velocity is related to morphological cell type in rat dorsal root ganglion neurones. J Physiol (Lond) 359:31-46.

Huang M, Chalfie M (1994) Gene interactions affecting mechanosensory transduction in Caenorhabditis elegans. Nature 367:467-470.

Hwang SW, Cho H, Kwak J, Lee SY, Kang CJ, Jung J, Cho S, Min KH, Suh YG, Kim D, Oh U (2000) Direct activation of capsaicin receptors by products of lipoxygenases: endogenous capsaicin-like substances. Proc Natl Acad Sci USA 97:6155-6160.

Jung J, Hwang SW, Kwak J, Lee SY, Kang CJ, Kim WB, Kim D, Oh U (1999) Capsaicin binds to the intracellular domain of the capsaicinactivated ion channel. J Neurosci 19:529-538.

Kim D, Sladek CD, Aguado-Velasco C, Mathiasen JR (1995) Arachidonic acid activation of a new family of $\mathrm{K}+$ channels in cultured rat neuronal cells. J Physiol (Lond) 484:643-660.

Lane JW, McBride DW Jr, Hamill OP (1991) Amiloride block of the mechanosensitive cation channel in Xenopus oocytes. J Physiol (Lond) 441:347-366.

Liedtke W, Choe Y, Marti-Renom MA, Bell AM, Denis CS, Sali A, Hudspeth AJ, Friedman JM, Heller S (2000) Vanilloid receptorrelated osmotically activated channel (VR-OAC), a candidate vertebrate osmoreceptor. Cell 103:525-535.

Maingret F, Fosset M, Lesage F, Lazdunski M, Honore E (1999) TRAAK is a mammalian neuronal mechano-gated $\mathrm{K}+$ channel. J Biol Chem 274:1381-1387.

Marchenko SM, Sage SO (1997) A novel mechanosensitive cationic channel from the endothelium of rat aorta. J Physiol (Lond) 498:419-425

Martin HA, Basbaum AI, Kwiat GC, Goetzl EJ, Levine JD (1987) Leukotriene and prostaglandin sensitization of cutaneous highthreshold $\mathrm{C}$ - and A-delta mechanonociceptors in the hairy skin of rat hindlimbs. Neuroscience 22:651-659.

McCarter GC, Reichling DB, Levine JD (1999) Mechanical transduction by rat dorsal root ganglion neurons in vitro. Neurosci Lett 273:179-182.

Mitani S, Du H, Hall DH, Driscoll M, Chalfie M (1993) Combinatorial control of touch receptor neuron expression in Caenorhabditis elegans. Development 119:773-783.

Oh U, Hwang SW, Kim D (1996) Capsaicin activates a nonselective cation channel in cultured neonatal rat. J Neurosci 16:1659-1667.

Opsahl LR, Webb WW (1994) Lipid-glass adhesion in giga-sealed patchclamped membranes. Biophys J 66:75-79.
Ouseph AK, Khasar SG, Levine JD (1995) Multiple second messenger systems act sequentially to mediate rolipram-induced prolongation of prostaglandin E2-induced mechanical hyperalgesia in the rat. Neuroscience 64:769-776.

Perl ER (1996) Cutaneous polymodal receptors: characteristics and plasticity. Prog Brain Res 113:21-37.

Sadoshima J, Takahashi T, Jahn L, Izumo S (1992) Roles of mechanosensitive ion channels, cytoskeleton, and contractile activity in stretchinduced immediate-early gene expression and hypertrophy of cardiac myocytes. Proc Natl Acad Sci USA 89:9905-9909.

Schaible HG, Schmidt RF (1988) Excitation and sensitization of fine articular afferents from cat's knee joint by prostaglandin E2. J Physiol (Lond) 403:91-104.

Small DL, Morris CE (1994) Delayed activation of single mechanosensitive channels in Lymnaea neurons. Am J Physiol 267:C598-C606.

Sokabe M, Sachs F, Jing Z (1991) Quantitative video microscopy of patch clamped membranes stress, strain, capacitance, and stretch channel activation. Biophys J 59:722-728.

Spruce AE, Standen NB, Stanfield PR (1985) Voltage-dependent ATPsensitive potassium channels of skeletal muscle membrane. Nature 316:736-738.

Taiwo YO, Levine JD (1988) Characterization of the arachidonic acid metabolites mediating bradykinin and noradrenaline hyperalgesia. Brain Res 458:402-406.

Taiwo YO, Levine JD (1991) Further confirmation of the role of adenyl cyclase and of cAMP-dependent protein kinase in primary afferent hyperalgesia. Neuroscience 44:131-135.

Taiwo YO, Bjerknes LK, Goetzl EJ, Levine JD (1989) Mediation of primary afferent peripheral hyperalgesia by the cAMP second messenger system. Neuroscience 32:577-580.

Takahashi A, Gotoh H (2000) Mechanosensitive whole-cell currents in cultured rat somatosensory neurons. Brain Res 869:225-230.

Tavernarakis N, Driscoll M (1997) Molecular modeling of mechanotransduction in the nematode Caenorhabditis elegans. Annu Rev Physiol 59:659-689.

Walker RG, Willingham AT, Zuker CS (2000) A Drosophila mechanosensory transduction channel. Science 287:2229-2234.

Willis Jr WD, Coggeshall RE (1991) Peripheral nerves and sensory receptors, Ch 2. In: Sensory mechanisms of the spinal cord (Willis WD, Coggeshall RE, eds), pp 13-45. New York: Plenum.

Winkelmann RK (1986) Sensory receptors of the skin. In: Spinal afferent processing, Ch 2 (Yaksh TL, ed), pp 19-81. New York: Plenum.

Yang XC, Sachs F (1989) Block of stretch-activated ion channels in Xenopus oocytes by gadolinium and calcium ions. Science 243:10681071 . 